\title{
First Degree Family History Cancer Unknown
}

National Cancer Institute

\section{Source}

National Cancer Institute. First Degree Family History Cancer Unknown. NCI Thesaurus. Code C160167.

The history of cancer of the parents, siblings or children of an individual is unknown. 